\title{
Technological Advances of Speed Control of Induction Motor with PI and Fuzzy Logic Controllers
}

\author{
Saahithi S, Rajashekar P Mandi
}

\begin{abstract}
At the present scenario, three-phase induction motors (IM) are having wide applications in the industries. So, the need for an effective controlling technique is compulsory. Various techniques are there to control the speed of IM. Soft computing techniques are having in a great improvement in the recent trends. This paper discusses on the scalar control technique of induction motor for conventional PI and fuzzy logic controller. The performance of an induction motor is simulated using MATLAB/Simulink with PI and fuzzy controllers, the results are analyzed and the techno feasibility of both the controllers is presented in detail. Torque-speed $(T-N)$ characteristics of an induction motor for a traditional PI model are considered and compared with rules-based fuzzy logic.
\end{abstract}

Index Terms: Fuzzy Logic, Induction motor, MATLAB/Simulink.

\section{INTRODUCTION}

With the developing technology, the DC motors which were used earlier are replaced by AC motors. Controlling the speed of an AC motor is done by using power electronic converters. Three phase induction motors are having very wide applications in the industry [1]. Three phase induction motors are also known as asynchronous motors. Especially squirrel cage type IMs are widely used because of its advantages like- rugged, easy to maintain, high efficiency. So, the aim of this simulation work is to control the speed of an IM and compare it with conventional PI and fuzzy logic. MATLAB/Simulink model is implemented for different circuits which are presented. The IM speed control is simulated using fuzzy logic also with MATLAB/fis. As the load torque on the motor increases, the motor speed will be decreased. Since the 3- $\varphi$ IMs runs at constant speed, controlling the speed is more complicated than the DC motor. So it is somewhat difficult to control the speed of the motor. Therefore an IM speed control is done for the cost of a decrease in its efficiency and low electric PF.An IM speed can be controlled either from Stator or the Rotor side [2-3].

The presented work focused on Stator side speed control. The method from the Stator side is as follows.

1. Frequency control or $\mathrm{V} / \mathrm{f}$

2. Change in number of stator poles

3. Control the Supply voltage

4. Adding variable resistance in the stator side

Revised Manuscript Received on March 5, 2020.

* Correspondence Author

Burri Ankaiah*, Assistant Professor,School of EEE, REVA University/,Bangalore, India. Email: burriankaiah@reva.edu.in

Dr.Rajashekar P.Mandi, Professor\&Director,School of EEE, REVA University, Banglore, India. Email: dir.eee@reva.edu.in
When supply is given to the stator of 3- $\varphi$ IM, the RMF is created which will be rotating with the synchronous speed. Hence, the EMF induced in the three phase induction motor is the same as the transformer.

\section{SCALAR CONTROL METHOD}

If the supply frequency varies, the Ns will change. But as the frequency decreases, there will be an increment in the flux. This flux increase can cause the rotor saturation and stator cores which further increase in no-load current of the motor. To overcome this effect, keep up the constant flux. This is possible only by changing voltage. Therefore, with a decrease in the frequency, flux increases. Simultaneously if there is a reduction in voltage, flux will also reduce [8]. This causes a change in flux, therefore, it remains constant.Hence maintain $\mathrm{V} / \mathrm{f}$ ratio constant. This is the reason this method is called V/f method of speed control [9].For the 3- $\varphi$ IM speed control by the V/f method, the supply voltage and frequency can be varied simply by using AC-DC-AC converter.

Equation of induced voltage of IM is given in equation (1)

$V_{e_{-} R M S}=4.44 \cdot K \cdot f \cdot N \cdot \phi$---------- (1)

Where

$V_{e_{-} R M S}-$ Voltage Induced in Stator, $f$ - Frequency

$N-$ No. of turns of stator voltage and

$\Phi$ - Stator flux linkage

According to the above equation, if the V/f ratio is maintained as constant, then the flux linkage will also be constant under the entire operating region of induction motor which makes the IM drive system as stable. The V/f curve of IM drive is provided in Fig 1.

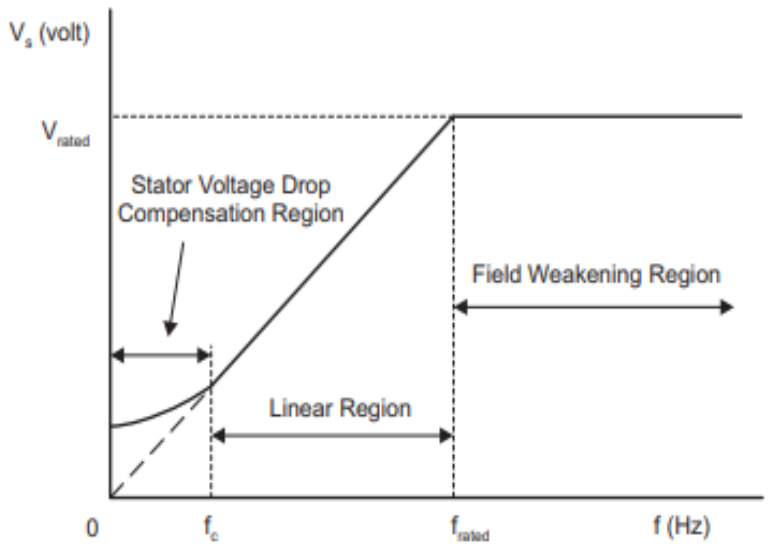

Fig.1. V/f Profile 


\section{A. Open loop Scalar control method}

This type of scalar control is used where the accuracy of speed is not much concern like in HVAC, fan applications. Here the frequency is calculated based on the reference speed and error in the actual measurement is deemed as acceptable provided [4] that no feedback is taken as shown in Fig 2.

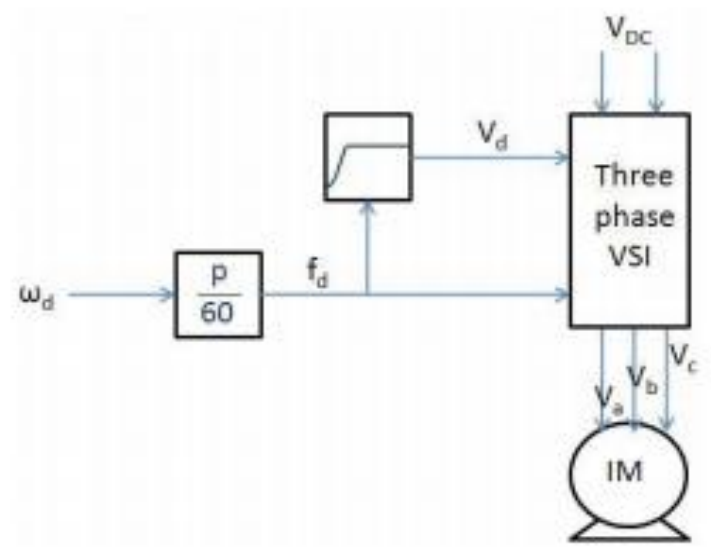

Fig.2. Open loop scalar control

\section{B. Closed loop Scalar control method}

The closed loop control provides a more accurate solution than that of open loop technique. The rotor speed is measured and given back to the controller with which an error between reference and measured speed is provided to PI controller [4]. The PI controller as shown in Fig 3, generates a reference signal so that the drive can achieve the reference speed.

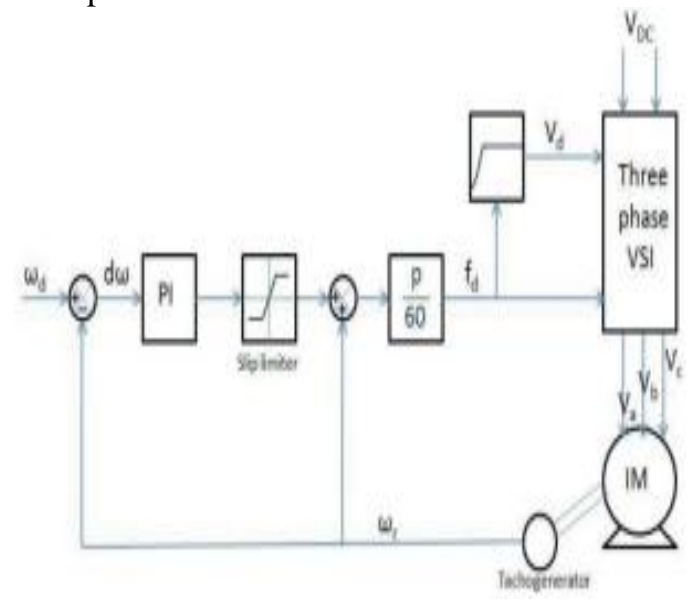

Fig.3. Closed loop scalar control

\section{FUZZY LOGIC (FL)}

Fuzzy logic is also soft computing technique. Fuzzy means which is not precise or having the clarity. The difference in human thinking and Boolean logic is the fuzzy logic. It is another class of Artificial Intelligence. But it has more recent applications than those of the expert systems. Problems that have fuzziness or vagueness will be dealt with FL. Fuzzy set theory FL based, an object has a DOM in a given set that may be in the range of 0 to 1 . Hence, bi-valued logic FL is often defined as multi-valued logic in contrast [7].

\section{A. Fuzzy Techniques}

There are four step fuzzy techniques employed in implementing fuzzy logic.

\section{Fuzzification \\ 2. Inference \\ 3. Composition \\ 4. Defuzzyfication}

\section{B. Fuzzy Sets}

Fuzzy sets are similar to mathematical sets. Those which involves the degrees of membership functions. A fuzzy set is the natural extension of classical set theory. These is the foundation of FL theory [1]. An accurate set always depends on 0 or 1 . But the fuzzy set will give the intermediate values from the help of membership function from 0 to 1 .The ranges of membership functions are called degrees of membership.

\section{SIMULATION}

Here the simulation is performed in both MATLAB/Simulink model and fuzzy fis simulation.The circuit is as shown in Fig 4, which shows the simulation circuit of Asynchorous Induction Motor for torque-speed characteristics. The Closed loop Scalar Control technique is applied to an Induction motor by considering parameters mentioned in the following table 1.

TABLE 1 RATING OF AN IM

\begin{tabular}{|l|l|}
\hline Parameters & Values \\
\hline Rated Power $\left(\mathrm{P}_{\text {rated }}\right)$ & $4 \mathrm{KW}$ \\
\hline Rated Voltage $\left(\mathrm{V}_{\text {rated }}\right)$ & $400 \mathrm{~V}$ \\
\hline System Frequency $(\mathrm{f})$ & $50 \mathrm{~Hz}$ \\
\hline Rated rotor Speed $(\mathrm{N})$ & $1430 \mathrm{rpm}$ \\
\hline Stator Resistance $\left(\mathrm{R}_{\mathrm{s}}\right)$ & $1.405 \mathrm{ohm}$ \\
\hline Rotor Resistance $\left(\mathrm{R}_{\mathrm{r}}\right)$ & $1.395 \mathrm{ohm}$ \\
\hline Stator Leakage Inductance $\left(\mathrm{L}_{\mathrm{ls}}\right)$ & $0.0058 \mathrm{H}$ \\
\hline Rotor Leakage Inductance $\left(\mathrm{L}_{\mathrm{lr}}\right)$ & $0.0058 \mathrm{H}$ \\
\hline Magnetization Inductance $\left(\mathrm{L}_{\mathrm{m}}\right)$ & $0.1722 \mathrm{H}$ \\
\hline Number of Poles $(\mathrm{P})$ & 4 \\
\hline
\end{tabular}

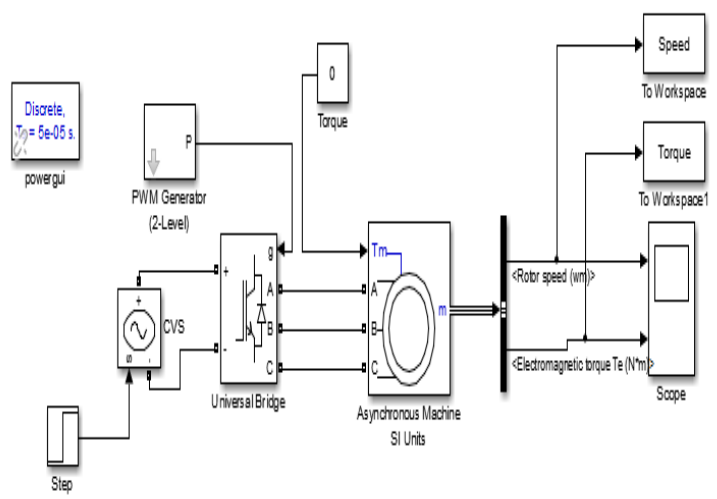

Fig.4. Simulink model for Open loop control 


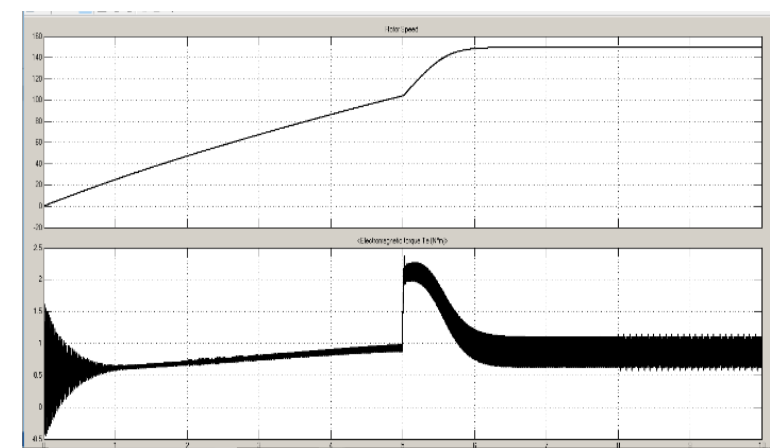

Fig.5. Rotor speed vs Electromagnetic torque plot for open loop control

The graph shows the initial oscillations are more from $t=$ 0-3 seconds. After $t=5$ seconds the grahs shows that more time taken to settle the output waveform.

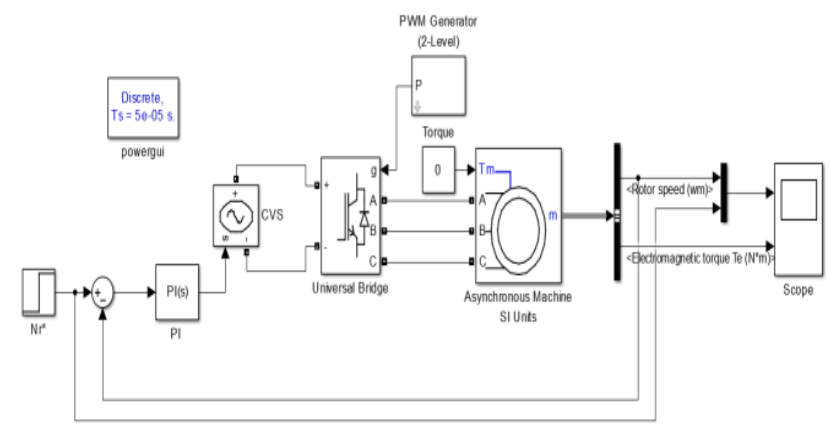

Fig.6. Simulation model for conventional PI control

In the above mentioned simulation model, the rotor speed reference is considered as mentioned in the following table 2 .

TABLE 2 ROTOR REFERENCE SPEED

\begin{tabular}{|c|c|}
\hline Time (Sec) & $\begin{array}{l}\text { Rotor speed Reference } \\
\text { (rad/s) }\end{array}$ \\
\hline 0 to 5 & 80 \\
\hline 5 to 10 & 120 \\
\hline
\end{tabular}

The simulation results of rotor speed and electromagnetic torque are as shown in Fig 5, for open loop control and Fig 6 , shows for the closed loop control.

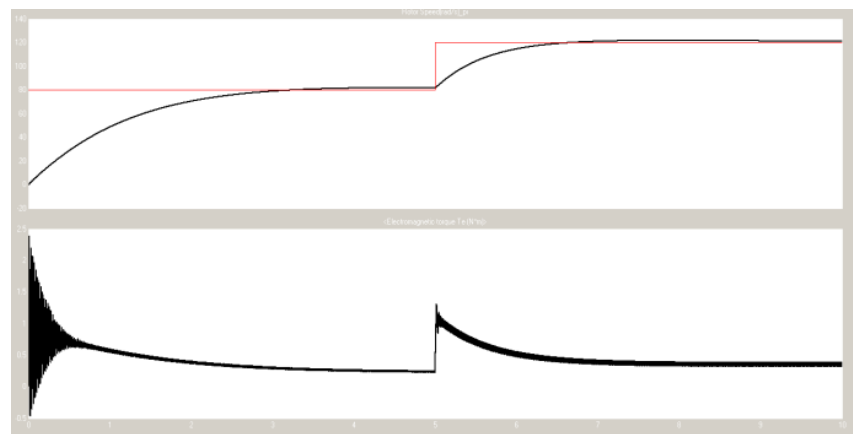

Fig.7. Rotor speed vs Electromagnetic Torque for closed loop control (PI)

Initially the rotor speed needs $3 \mathrm{~s}$ to reach the reference speed and after $\mathrm{t}=5 \mathrm{~s}$ the reference speed changes from 80 $\mathrm{rad} / \mathrm{s}$ to $120 \mathrm{rad} / \mathrm{s}$ and the rotor speed reaches the reference at $\mathrm{t}=7 \mathrm{~s}$. Here the graph shows the initial oscillations are more from $\mathrm{t}=0-3$ seconds. After $\mathrm{t}=5$ seconds the grahs shows that the output is settling quickly.

Induction motor with the same parameters is simulated by connecting fuzzy logic block. The delay is also considered. For the same reference speed, the performance of an induction motor is simulated using MATLAB/Simulink.

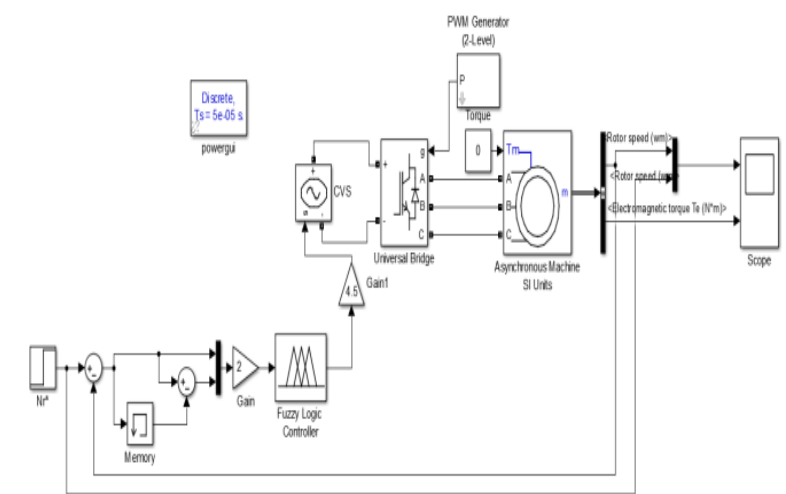

Fig.8. Simulation model for fuzzy control

The fuzzy block is connected in place of conventional PI controller. As shown in the above mentioned simulation circuit (Fig 8), the rule list for the fuzzy controller is shown below:

1. $(\mathrm{E}==\mathrm{NL}) \&(\Delta \mathrm{E}==\mathrm{NL})=>($ control variable $=\mathrm{PL})$

2. $(\mathrm{E}==\mathrm{NL}) \&(\Delta \mathrm{E}==\mathrm{NM})=>($ control variable $=\mathrm{PL})$

3. $(\mathrm{E}==\mathrm{NL}) \&(\Delta \mathrm{E}==\mathrm{Z})=>($ control variable $=\mathrm{PL})$

4. $(\mathrm{E}==\mathrm{NL}) \&(\Delta \mathrm{E}==\mathrm{PM})=>($ control variable $=\mathrm{PM})$

5. $(\mathrm{E}==\mathrm{NL}) \&(\Delta \mathrm{E}==\mathrm{PL})=>($ control variable $=\mathrm{Z})$

6. $(\mathrm{E}==\mathrm{NM}) \&(\Delta \mathrm{E}==\mathrm{NL})=>($ control variable $=\mathrm{PL})$

7. $(\mathrm{E}==\mathrm{NM}) \&(\Delta \mathrm{E}==\mathrm{NM})=>($ control variable $=\mathrm{PM})$

8. $(\mathrm{E}==\mathrm{NM}) \&(\Delta \mathrm{E}==\mathrm{Z})=>($ control variable $=\mathrm{PM})$

9. $(\mathrm{E}==\mathrm{NM}) \&(\Delta \mathrm{E}==\mathrm{PM})=>($ control variable $=\mathrm{Z})$

10. $(\mathrm{E}==\mathrm{NM}) \&(\Delta \mathrm{E}==\mathrm{PL})=>($ control variable $=\mathrm{PM})$

11. $(\mathrm{E}==\mathrm{Z}) \&(\Delta \mathrm{E}==\mathrm{NL})=>($ control variable $=\mathrm{PL})$

12. $(\mathrm{E}==\mathrm{Z}) \&(\Delta \mathrm{E}==\mathrm{NM})=>($ control variable $=\mathrm{PM})$

13. $(\mathrm{E}==\mathrm{Z}) \&(\Delta \mathrm{E}==\mathrm{Z})=>($ control variable $=\mathrm{Z})$

14. $(\mathrm{E}==\mathrm{Z}) \&(\Delta \mathrm{E}==\mathrm{PM})=>($ control variable $=\mathrm{PM})$

15. $(\mathrm{E}==\mathrm{Z}) \&(\Delta \mathrm{E}==\mathrm{PL}) \Rightarrow($ control variable $=\mathrm{PL})$

16. $(\mathrm{E}==\mathrm{PM}) \&(\Delta \mathrm{E}==\mathrm{NL}) \Rightarrow($ control variable $=\mathrm{PM})$

17. $(\mathrm{E}==\mathrm{PM}) \&(\Delta \mathrm{E}==\mathrm{NM})=>($ control variable $=\mathrm{Z})$

18. $(\mathrm{E}==\mathrm{PM}) \&(\Delta \mathrm{E}==\mathrm{Z})=>($ control variable $=\mathrm{PM})$

19. $(\mathrm{E}==\mathrm{PM}) \&(\Delta \mathrm{E}==\mathrm{PM})=>($ control variable $=\mathrm{PM})$

20. $(\mathrm{E}==\mathrm{PM}) \&(\Delta \mathrm{E}==\mathrm{PL})=>($ control variable $=\mathrm{PL})$

21. $(\mathrm{E}==\mathrm{PL}) \&(\Delta \mathrm{E}==\mathrm{NL})=>($ control variable $=\mathrm{Z})$

22. $(\mathrm{E}==\mathrm{PL}) \&(\Delta \mathrm{E}==\mathrm{NM})=>($ control variable $=\mathrm{PL})$

23. $(\mathrm{E}==\mathrm{PL}) \&(\Delta \mathrm{E}==\mathrm{Z})=>($ control variable $=\mathrm{PL})$

24. $(\mathrm{E}==\mathrm{PL}) \&(\Delta \mathrm{E}==\mathrm{PM}) \Rightarrow($ control variable $=\mathrm{PL})$

25. $(\mathrm{E}==\mathrm{PL}) \&(\Delta \mathrm{E}==\mathrm{PL})=>($ control variable $=\mathrm{PL})$

The fis results of fuzzy controller is as shown in Fig 9. 


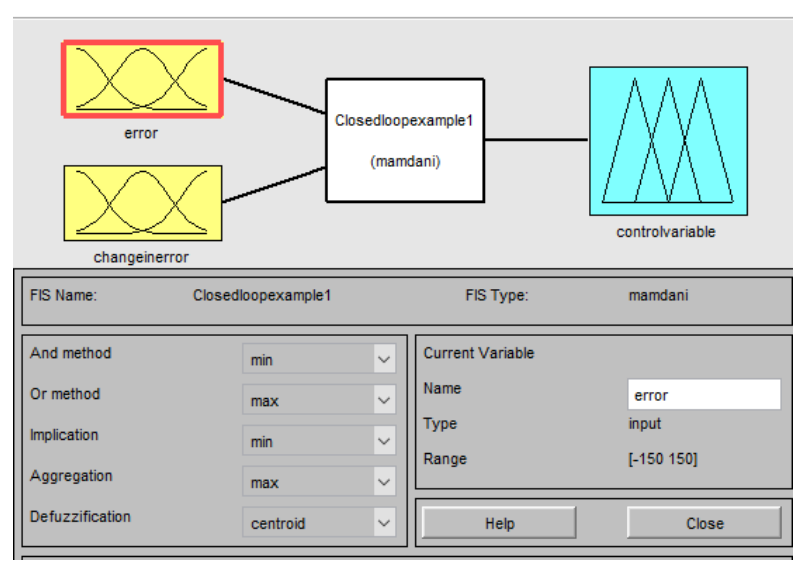

Fig.9. MATLAB/fis editor

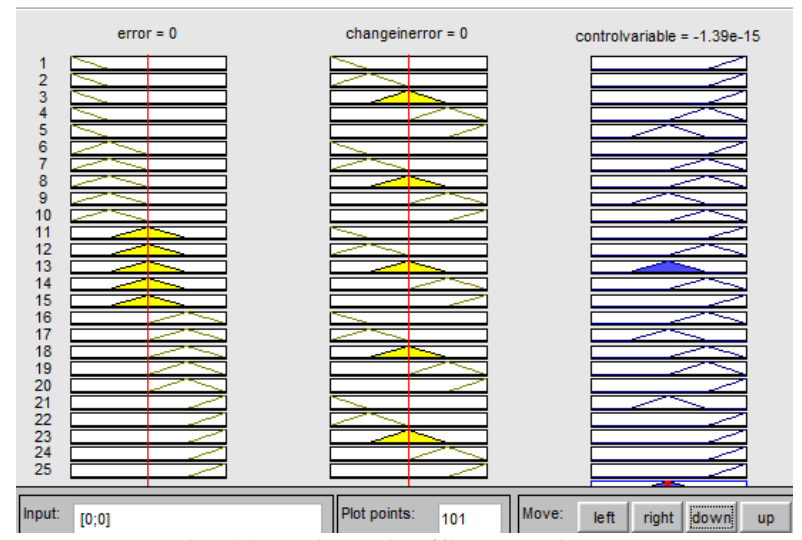

Fig.10. MATLAB/fis ruleviewer

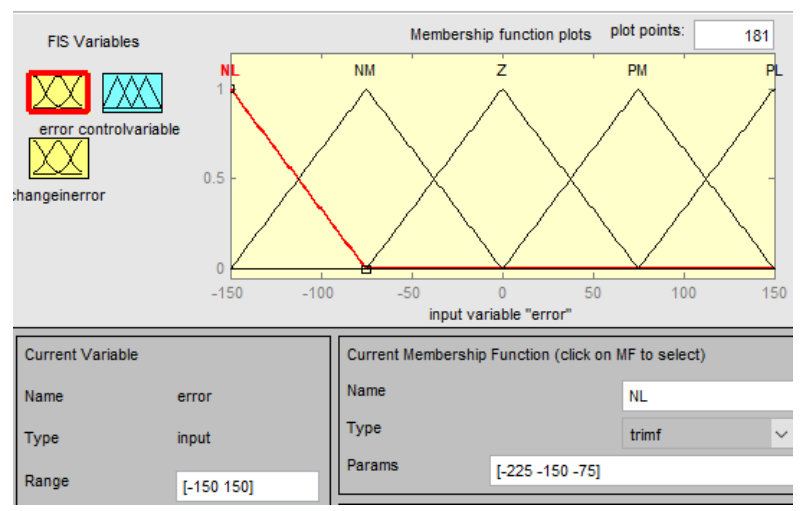

Fig.11. MFs for error as input

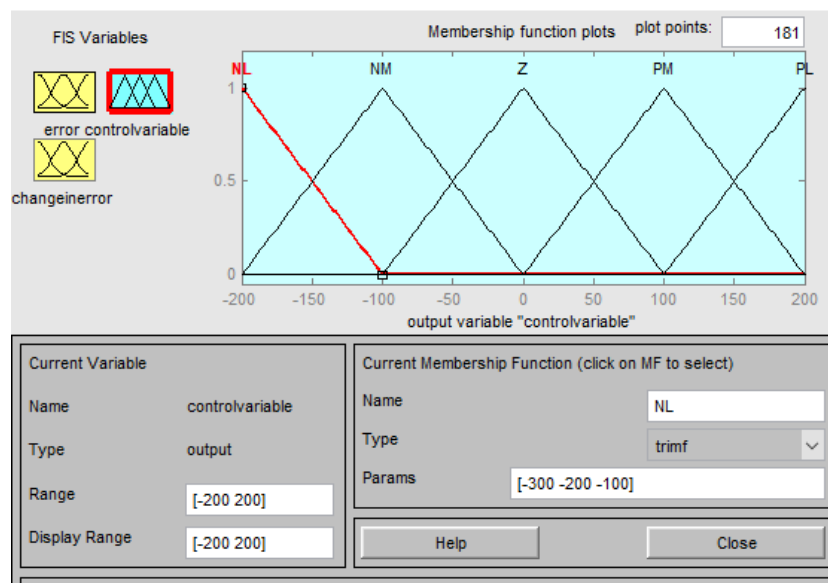

Fig.12. MFs for output

The simulink results of fuzzy controller is as shown in Fig 14.

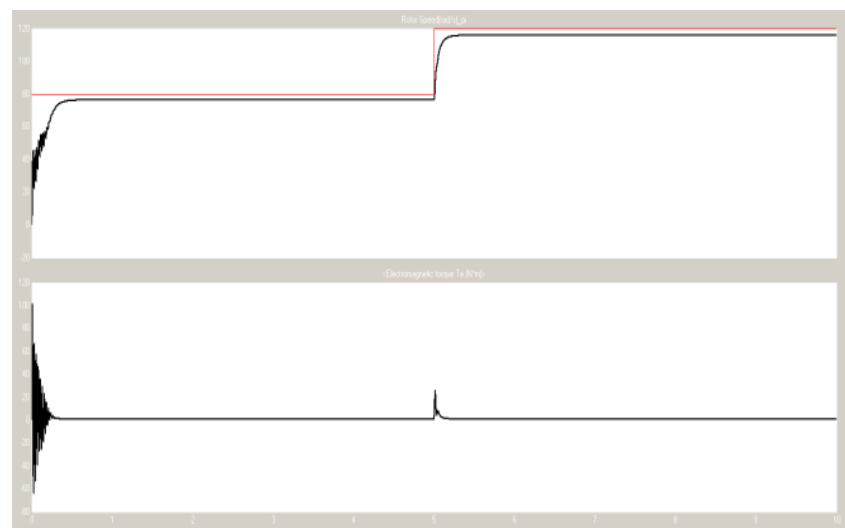

Fig.14. Rotor spped vs Electromagnetic torque plot for Closed loop (Fuzzy)

In the above graph, the rotor speed took nearly $0.5 \mathrm{~s}$ to reach the reference speed which changes from $80 \mathrm{rad} / \mathrm{s}$ to $120 \mathrm{rad} / \mathrm{s}$ at $\mathrm{t}=5 \mathrm{~s}$ and the measured rotor speed reaches $120 \mathrm{rad} / \mathrm{s}$ at $\mathrm{t}=5.3 \mathrm{~s}$.

Fig.5, Fig.7 and Fig.14 output graphs shows that there is an improvement when the fuzzy controller is used. Here the graph shows the initial oscillations were reduced from $t=$ 0-3 seconds. After $t=5$ seconds the grahs shows that the output is settling very fast.

\section{CONCLUSION AND FUTURE WORK}

Speed control of three phase IM with Scalar control technique for both open loop and closed loop is presented in this paper. The comparative analysis of scalar and vector control strategies were discussed. The simulation results were discussed for the torque and speed characteristics of an induction motor for conventional PI and fuzzy controllers. In both cases we have replaced the PI with fuzzy logic controllers and increased the transient performance of speed control. In the conventional PI controllers, the mathematical calculation will be more and complex., but in the fuzzy controller, the membership functions can be changed and can get very accurate result. The results shows an improvement in transient response. The improvement in the motor performance is observed for all three simulation circuits and concluded that fuzzy will be giving better results and performance. It can also be implemented for a vector control method for better dynamic conditions. This work can be further studied and improved by using various optimization techniques.

\section{REFERENCES}

1. Pratyush Verma, Rohit Saxena, Chitra A, Razia Sultana, "Implementing Fuzzy PI Scalar Control of Induction Motor", IEEE International Conference on Power, Control, Signals and Instrumentation Engineering (ICPCSI-2017)

2. Juan Moreano Peña, Edilberto Vásquez Díaz, "Implementation of V/f scalar control for speed regulation of a three-phase induction motor", IEEE Transactions 2016.

3. P. M. Menghal , Dr. A. Jaya Laxmi " "Scalar Control of An Induction Motor Using Artificial Intelligent Controller", IEEE Transactions 2014.

4. M. Menghal, Dr. Jayalaxmi, "Dynamic Modeling, Simulation \& Analysis of Induction Motor Drives", IEEE transactions 2014.

5. Karkar H. M., "Improvement Speed Regulation In Open Loop V/F Control of Three Phase Induction Motor Drive", IJDI-ERET, pp. $52-58,2013$ 
6. Texas Instruments, "Scalar (V/f) Control of 3-Phase Induction Motors", Application Report SPRABQ8-July 2013.

7. Ali M. Eltamaly, A. I. Alolah, and Basem M. Badr, "Fuzzy Controller for Three Phases Induction Motor Drives", IEEE Transactions, 2010.

8. Neha Sharma, Vijay Kumar Garg, "A Comparative Analysis of Scalar and Vector Control of Induction motor drive", Impending Power Demand and Innovative Energy Paths.

9. Pabitra Kumar Behera, Manoj Kumar Behera, Amit Kumar Sahoo, "A Comparative Analysis of Scalar and Vector Control of Induction motor through modeling and simulation", International Journal of Innovative Research in Electrical \& Electronics Instrumentation and Control Engineering.

10. Swagat Pati, Manas Patnaik, Abinash Panda, "Comparative Performance Analysis of Fuzzy PI, PD and PID Controllers used in a Scalar Controlled induction motor drive", International Conference on Circuit, Power and Computing Technologies [ICCPCT], IEEE Conference.

\section{AUTHORS PROFILE}

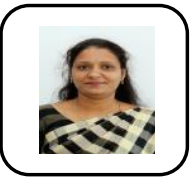

Saahithi S, Research Scholar, School of Electrical and Electronics Engineering, REVA University. She obtained her Master's Degree (M.Tech) in Computer Applications in Industrial Drives from MSRIT Bangalore. She is currently pursuing her $\mathrm{PhD}$ in the field of Power electronics and drives under the guidance of Dr. Rajashekar P. Mandi, Director, School of EEE, REVA University Bangalore.

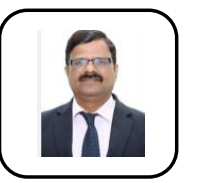

Dr. Rajashekar P. Mandi, Director, School of Electrical and Electronics Engineering, REVA University, holds Doctorate from NITK, Surathkal in the area of "Power and Energy" and holds M. Tech. degree with 3rd Rank in "Energy Systems Engineering" from BV Bhoomaraddi College of Engineering \& Technology, Hubli of Visveswaraiah Technology University (VTU), Belgaum. He also obtained Master of Computer Application (MCA) degree from IGNOU, New Delhi. He is a certified energy auditor from Bureau of Energy Efficiency (BEE), Govt. of India. He has three years of teaching experience. Prior to venturing into the field of academia, he had worked in Central Power Research Institute (CPRI), a premier research institute under the Ministry of Power (MoP), Govt. of India, for more than 26 years in the area of Power system simulation, Power distribution system strengthening, Power quality audit in process industries \& electrical distribution system, Electrical Safety audit in process industries, Energy conservation, Energy audit in thermal \& hydro power plants (more than 120 power plants), process industries, institutions \& buildings, Power system, Renewable energy systems, testing of Lighting equipment and solar PV systems. His research interests include smart grid, microgrid, LVDC, hybrid power system, renewable energy systems, energy conservation, strengthening of electrical distribution systems, electrical safety, power quality, LED lighting systems, etc. Presently he is guiding 8 $\mathrm{PhD}$ research scholars, guided 15 MTech. Projects and 15 BTech. Projects. He had written 3 book chapters on energy conservation in Thermal Power plants and 2 book chapters in distributed power generation. He had published more than 141 technical papers in International \& Indian Journals, Conferences \& Seminars in the field of energy conservation, power quality, LED lighting system and renewable energy systems. 